NASA/TM-2002-211871

AIAA-2002-4895

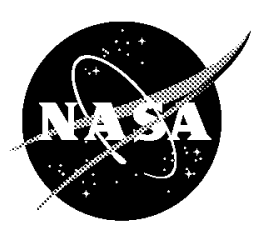

\title{
A Method of Efficient Inclination Changes for Low-Thrust Spacecraft
}

Robert Falck and Leon Gefert

Glenn Research Center, Cleveland, Ohio 
The NASA STI Program Office ... in Profile

Since its founding, NASA has been dedicated to the advancement of aeronautics and space science. The NASA Scientific and Technical Information (STI) Program Office plays a key part in helping NASA maintain this important role.

The NASA STI Program Office is operated by Langley Research Center, the Lead Center for NASA's scientific and technical information. The NASA STI Program Office provides access to the NASA STI Database, the largest collection of aeronautical and space science STI in the world. The Program Office is also NASA's institutional mechanism for disseminating the results of its research and development activities. These results are published by NASA in the NASA STI Report Series, which includes the following report types:

- TECHNICAL PUBLICATION. Reports of completed research or a major significant phase of research that present the results of NASA programs and include extensive data or theoretical analysis. Includes compilations of significant scientific and technical data and information deemed to be of continuing reference value. NASA's counterpart of peerreviewed formal professional papers but has less stringent limitations on manuscript length and extent of graphic presentations.

- TECHNICAL MEMORANDUM. Scientific and technical findings that are preliminary or of specialized interest, e.g., quick release reports, working papers, and bibliographies that contain minimal annotation. Does not contain extensive analysis.

- CONTRACTOR REPORT. Scientific and technical findings by NASA-sponsored contractors and grantees.
- CONFERENCE PUBLICATION. Collected papers from scientific and technical conferences, symposia, seminars, or other meetings sponsored or cosponsored by NASA.

- SPECIAL PUBLICATION. Scientific, technical, or historical information from NASA programs, projects, and missions, often concerned with subjects having substantial public interest.

- TECHNICAL TRANSLATION. Englishlanguage translations of foreign scientific and technical material pertinent to NASA's mission.

Specialized services that complement the STI Program Office's diverse offerings include creating custom thesauri, building customized databases, organizing and publishing research results ... even providing videos.

For more information about the NASA STI Program Office, see the following:

- Access the NASA STI Program Home Page at http://www.sti.nasa.gov

- E-mail your question via the Internet to help@sti.nasa.gov

- Fax your question to the NASA Access Help Desk at 301-621-0134

- Telephone the NASA Access Help Desk at 301-621-0390

- Write to: NASA Access Help Desk NASA Center for AeroSpace Information 7121 Standard Drive Hanover, MD 21076 
NASA/TM-2002-211871

AIAA-2002-4895

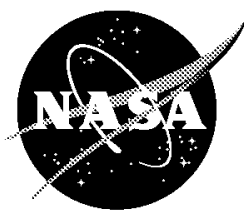

\section{A Method of Efficient Inclination Changes for Low-Thrust Spacecraft}

Robert Falck and Leon Gefert

Glenn Research Center, Cleveland, Ohio

Prepared for the

Astrodynamics Specialist Conference and Exhibit

cosponsored by the American Institute of Aeronautics and Astronautics and the American Astronautical Society

Monterey, California, August 5-8, 2002

National Aeronautics and

Space Administration

Glenn Research Center 
This report is a formal draft or working paper, intended to solicit comments and ideas from a technical peer group.

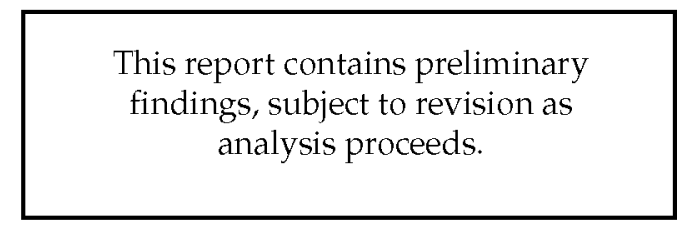

Available from

NASA Center for Aerospace Information 7121 Standard Drive

National Technical Information Service 5285 Port Royal Road Hanover, MD 21076 


\title{
A METHOD OF EFFICIENT INCLINATION CHANGES FOR LOW-THRUST SPACECRAFT
}

\author{
Robert Falck ${ }^{*}$ and Leon Gefert \\ National Aeronautics and Space Administration \\ Glenn Research Center \\ Cleveland, Ohio 44135
}

\section{$\underline{\text { ABSTRACT }}$}

The evolution of low-thrust propulsion technologies has reached a point where such systems have become an economical option for many space missions. The development of efficient, low trip time control laws has received an increasing amount of attention in recent years, though few studies have examined the subject of inclination changing maneuvers in detail. A method for performing economical inclination changes through the use of an efficiency factor is derived from Lagrange's planetary equations. The efficiency factor can be used to regulate propellant expenditure at the expense of trip time. Such a method can be used for discontinuous-thrust transfers that offer reduced propellant masses and trip-times in comparison to continuous thrust transfers, while utilizing thrusters that operate at a lower specific impulse. Performance comparisons of transfers utilizing this approach with continuous-thrust transfers are generated through trajectory simulation and are presented in this paper.

\section{NOMENCLATURE}

a semi-major axis

e eccentricity

$i \quad$ inclination

$\omega \quad$ argument of periapsis

$v \quad$ true anomaly

$\mathrm{I}_{\mathrm{sp}} \quad$ specific impulse

$\mathrm{p} \quad$ spacecraft propulsive power

$\eta_{\mathrm{p}} \quad$ spacecraft power subsystem efficiency

$\mathrm{m}_{0} \quad$ initial spacecraft mass

$\mathrm{m}_{\mathrm{p}} \quad$ spacecraft propellant mass expenditure

MET mission elapsed time

$\mathrm{t}$ time

$r \quad$ radius

n mean motion

W magnitude of orbit-normal thrust vector

$\eta_{\Delta \mathrm{i}} \quad$ efficiency of inclination change in given orbit

$\chi \quad$ minimum magnitude of $\eta_{\Delta i}$ to enable thrusting

\section{$\underline{\text { INTRODUCTION }}$}

The evolution of low-thrust propulsion technologies has reached a point where such systems have become an economical option for many space mission applications. The development of efficient control laws has received an increasing amount of attention in recent years, though few studies have examined the subject of inclination changing maneuvers in detail.

The topics covered in this paper are the results of trajectory design work in which large changes in inclination were required for orbits of moderate eccentricity. The resulting methods allow the tradeoff between trip time and propellant mass to be quantified, thus giving a mission designer a convenient way of managing mission performance. There is a wide array of applications, including transfers between low-Earth orbit, the Moon, and other planets, where a significant change in inclination is likely to be required at some point in the mission.

Using Lagrange's planetary equations as a starting point, an efficiency factor can be derived that normalizes the time-rate of change in inclination at a given point in the orbit by the maximum value of $\mathrm{di} / \mathrm{dt}$ in the orbit. Previous work along these lines has been conducted for in-plane orbital transfers utilizing discontinuous-thrust ${ }^{1}$ and for continuous-thrust orbit raising maneuvers incorporating inclination changes ${ }^{2}$. Methods for managing inclination through the efficiency factor for both continuous-thrust and discontinuous-thrust cases will be explained in the following sections of this paper.

\section{BEHAVIOR OF $\mathrm{di} / \mathrm{dt}$}

From Lagrange's planetary equations, the time-rate of change in inclination can be written ${ }^{3}$ :

$$
\frac{d i}{d t}=\frac{W r \cos (\omega+v)}{n a^{2} \sqrt{1-e^{2}}}
$$

* Case Western Reserve University, Student Engineer 
Using the expression for radius in Keplerian elements, Equation 1 can be written

$$
\frac{d i}{d t}=\frac{W \sqrt{1-e^{2}} \cos (\omega+v)}{n a(1+e \cos (v))}
$$

Plots of the magnitude of $\mathrm{di} / \mathrm{dt}$, from Equation 2, with respect to true anomaly and eccentricity are shown in Figures 1 and 2. A value of 1.0 is used for $\mathrm{W}, \mathrm{n}$, and a.

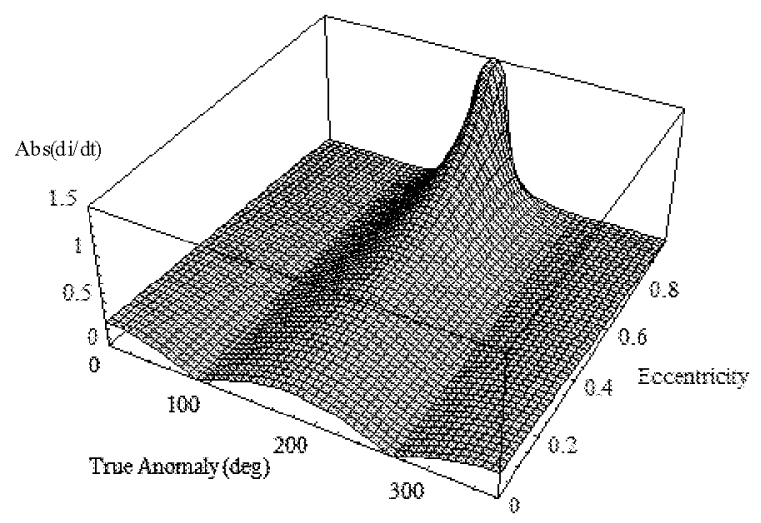

Figure 1: $\mathrm{Abs}(\mathrm{di} / \mathrm{dt})$ vs. True Anomaly And Eccentricity, $\omega=0^{\circ}$

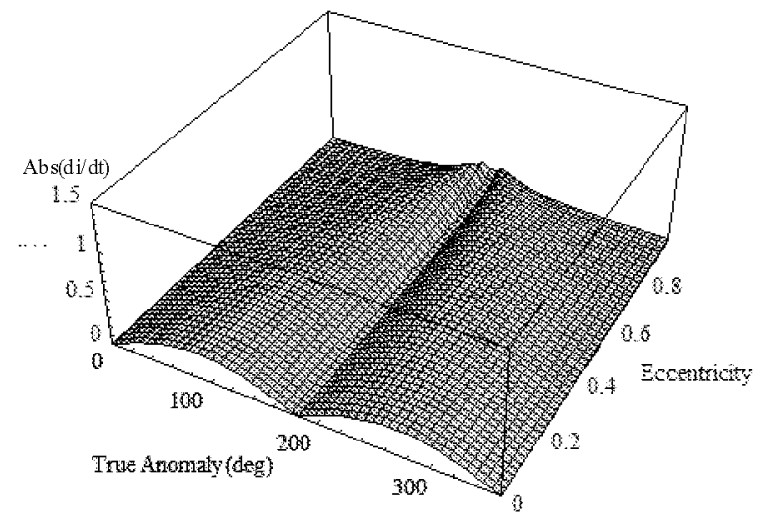

Figure 2: $\mathrm{Abs}(\mathrm{di} / \mathrm{dt})$ vs. True Anomaly and Eccentricity, $\omega=0^{\circ}$

Note that the zeros always occur on the antinodal lines and the behavior is sinusoidal at an eccentricity of zero. As eccentricity is increased the behavior deviates from the sinusoidal case due to the presence of the radius term in the numerator of Equation 1. This suggests that sinusoidal inclination control laws developed in the past are not well suited for orbits of significant eccentricity.

\section{CONTROL LAW APPLICAIONS}

Two control-laws are considered here. The first is a continuous-thrust case in which orbit-normal thrust is scaled by the magnitude of di/dt. Excess thrust is diverted to the in-plane components of thrust to control semi-major axis or eccentricity as the mission requires. The second control law completely suspends orbitnormal thrust when $\mathrm{di} / \mathrm{dt}$ is arbitrarily deemed to be unreasonably low. In this case the $\mathrm{I}_{\mathrm{sp}}$ may be lowered, if possible, to reduce the time required to perform the inclination change. The result is a maneuver requiring less propellant mass to achieve a trip time equal to that of the continuous-thrust case, as will be demonstrated later in this paper.

\section{Continuous-Thrust Control Law Derivation}

The effectiveness of performing a change in inclination at a given point in an orbit may be gauged by comparing the value of $\mathrm{di} / \mathrm{dt}$ per unit of orbit-normal thrust at a given point in the orbit with the maximum value of $\mathrm{di} / \mathrm{dt}$ as a function of true anomaly. The resulting efficiency factor $\left(\eta_{\Delta i}\right)$ may be used to scale the out of plane thrust.

The first step is to determine the extrema of Equation 2. The sign of $\mathrm{di} / \mathrm{dt}$ is ignored as only the magnitude of the extrema is of interest. Thrust is assumed to be considerably low such that all elements aside from true anomaly are constant through a single orbital period. Equation 2 can be effectively simplified by removing all terms that are assumed to be constant, giving equation 3 :

$$
\frac{d i}{d t}=\frac{\cos \omega \cdot \cos v-\sin \omega \cdot \sin v}{(1+e \cdot \cos v)} \cdot \text { Const }
$$

Taking the derivative of Equation 2 with respect to $v$ and solving for the zeros yields the extrema:

$$
\begin{aligned}
& v=-\sin ^{-1}(e \sin (\omega))-\omega \\
& v=\sin ^{-1}(e \sin (\omega))-\omega+180^{\circ}
\end{aligned}
$$

The absolute maximum magnitude of $\mathrm{di} / \mathrm{dt}$ can then be determined by comparing the results when these values are used in Equation 3. Now that $\mathrm{di} / \mathrm{dt}_{\max }$ is known, the ratio of $\mathrm{di} / \mathrm{dt}$ at the current true anomaly to $\mathrm{di} / \mathrm{dt}_{\max }$ can be used to quantify the efficiency of orbitnormal thrusting in changing the inclination of an orbit. The constant terms will cancel, and can therefore be neglected. The efficiency of orbit normal thrusting to achieve an inclination change can then be defined as follows: 


$$
\eta_{\Delta i}=\frac{d i / d t}{d i / d t_{\max }}=\frac{\cos \omega \cos v-\sin \omega \sin v}{d i / d t_{\max }(1+e \cos v)}
$$

Figures 3 through 5 show values of $\eta_{\Delta \mathrm{i}}$ mapped onto various orbits. Note that the magnitude of $\mathrm{di} / \mathrm{dt}$ is much larger near apoapsis for an orbit of significant eccentricity.

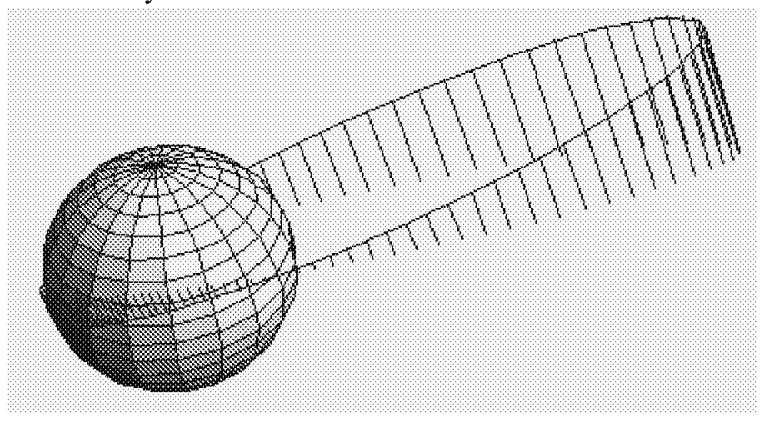

Figure 3: Orbit-Normal Thrust Vectors and Efficiency of Inclination Change, $\omega=0^{\circ}, \mathrm{e}=0.5$

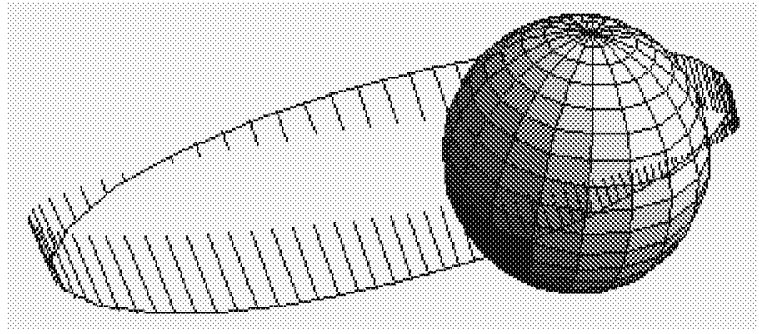

Figure 4: Orbit-Normal Thrust Vectors and Efficiency of Inclination Change, $\omega=90^{\circ}, \mathrm{e}=0.5$

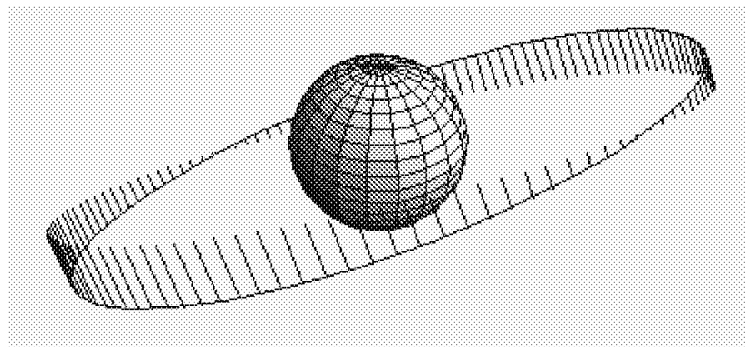

Figure 5: Orbit-Normal Thrust Vectors and Efficiency of Inclination Change, $\omega=0^{\circ}, \mathrm{e}=0.0$

\section{Discontinuous-Thrust Control Law Derivation}

As has previously been demonstrated for in-plane control laws by Gefert and Hack ${ }^{1}$, lower trip times and propellant mass expenditures may be achieved with thrusters of lower $\mathrm{I}_{\mathrm{sp}}$ by coasting during portions of the orbit where thrust has relatively little effect. In the case of an inclination change, $\eta_{\Delta \mathrm{i}}$ can be used to quantify the effectiveness of orbit-normal thrust in changing a spacecraft's inclination at any given point.

Orbit-normal thrusting will be suspended when $\eta_{\Delta i}$ drops below some threshold value, henceforth referred to as $\chi$. In the extreme cases, $\chi=1.0$ will result in infinitesimally short bursts of thrust at the true anomaly of $\mathrm{di} / \mathrm{dt}_{\max }$ given by Equation $2 \mathrm{and} /$ or Equation 3 . The other extreme, $\chi=0.0$, will result in continuous orbitnormal thrusting. The value of $\chi$ that will provide the desired tradeoff between trip time and propellant expenditure will, of course, vary from mission to mission. Figure 6, below, illustrates regions of thrusting and coasting for an eccentric orbit.

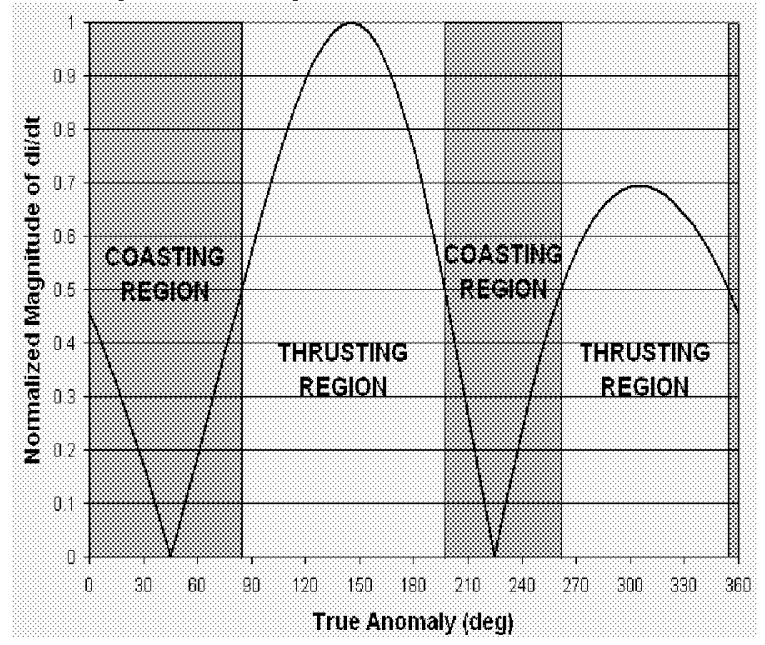

Figure 6: Thrusting and Coasting Regions for $\mathrm{e}=0.25$, $\omega=45^{\circ}$, and $\chi=0.5$

For this case the values of true anomaly at which $\eta_{\Delta \mathrm{i}}$ rises above or drops below $\chi$ are desired, so that thrusting can be suspended and resumed at the appropriate points in the orbit. It is assumed that $\mathrm{di} / \mathrm{dt}_{\max }$ is known from Equations 3 through 5 . The values of true anomaly which satisfy the following equation are sought:

$$
\eta_{\Delta i}=\frac{d i / d t}{d i / d t_{\max }}=\chi
$$

Using the reduced definition of di/dt given by Equation 3, Equation 7 becomes

$$
\frac{\cos \omega \cos v-\sin \omega \sin v}{(1+e \cos v)}=\chi \cdot \frac{d i}{d t_{\max }}
$$


Solving for $v$ yields the following:

$$
v=\cos ^{-1}\left(\frac{X}{\sqrt{Y^{2}+1}}\right) \cdot \operatorname{sign}(Y)-\tan ^{-1}(Y)
$$

and

$$
v=\cos ^{-1}\left(\frac{X}{-\sqrt{Y^{2}+1}}\right) \cdot \operatorname{sign}(Y)-\tan ^{-1}(Y)+180^{\circ}
$$

where

and

$$
X=\frac{\chi \cdot \frac{d i}{d t}_{\max }}{\cos (\omega)-\chi \cdot \frac{d i}{d t_{\max }} \cdot e}
$$

$$
Y=\frac{\sin (\omega)}{\cos (\omega)-\chi \cdot \frac{d i}{d t_{\text {max }}} \cdot e}
$$

Again, since only the magnitude of $\mathrm{di} / \mathrm{dt}$ is of interest here, Equations 9 and 10 must be solved for both positive and negative values of $\chi$. Two or four solutions will be generated, depending on the threshold value and the eccentricity of the orbit. The boundaries between the thrusting and coasting regions in Figure 6 were determined using this method.

\section{COMPUTATIONAL RESULTS}

Performance comparisons between the discontinuous-thrust control law discussed above, and optimal continuous-thrust inclination changes are shown on the following pages. Three cases are considered below, to give the reader some indication of the benefits available with discontinuous-thrust inclination control in various situations.

Optimal continuous-thrust cases are generated using SEPSPOT ${ }^{4}$, a low-thrust trajectory optimization program that uses an orbital averaging integration method, and uses calculus of variations to find minimumtime transfers. Discontinuous-thrust control laws were generated via SNAP, a RK78 trajectory propagation tool used under development at NASA Glenn Research Center. The discontinuous-thrust examples below were integrated in Cartesian coordinates. All tests were run neglecting j2 and higher order gravity effects, SEPSPOT and SNAP would both be expending propellant only $t$ achieve the desired inclination change. The spacecraft specifications for the following examples are as follows: $\mathrm{p}=75 \mathrm{kWe}$

$\eta_{\mathrm{p}}=0.70$

$\mathrm{m}_{0}=10000 \mathrm{~kg}$

\section{Example 1: Circular Orbit Inclination Change}

In the example below the case of an inclination change of a circular orbit is examined. Since the radius remains constant throughout an orbit, Equation 3 reduces to a simple cosine function.

The purpose of this example is to show whether a discontinuous-thrust inclination change control law can provide any significant propellant mass or trip time benefits over the continuous-thrust case at low eccentricities.

$$
\begin{array}{ll}
\text { Initial Orbit: } & \text { Final Orbit: } \\
\mathrm{a}=42161 \mathrm{~km} & \mathrm{a}=42161 \mathrm{~km} \\
\mathrm{e}=0.000 & \mathrm{e}=0.000 \\
i=28.45^{\circ} & i=51.6^{\circ} \\
\Omega=0^{\circ} & \Omega=0^{\circ} \\
\omega=0^{\circ} & \omega=0^{\circ}
\end{array}
$$

Table 1: SEPSPOT Results from Example 1

\begin{tabular}{|c|c|c|}
\hline $\begin{array}{c}\mathrm{I}_{\mathrm{sp}} \\
(\mathrm{sec})\end{array}$ & $\begin{array}{c}\text { MET } \\
(\text { days })\end{array}$ & $\begin{array}{c}\mathrm{m}_{\mathrm{p}} \\
(\mathrm{kg})\end{array}$ \\
\hline 3800 & 76.1 & 497 \\
3500 & 70.0 & 539 \\
3000 & 59.7 & 626 \\
\hline
\end{tabular}

Table 2: Discontinuous-thrust Results for Example 1

\begin{tabular}{|c|c|c|c|c|c|c|}
\hline \multirow{2}{*}{$\chi$} & \multicolumn{2}{|c|}{$3800 \mathrm{sec}$} & \multicolumn{2}{c|}{$3500 \mathrm{sec}$} & \multicolumn{2}{c|}{$3000 \mathrm{sec}$} \\
\cline { 2 - 7 } & $\begin{array}{c}\text { MET } \\
\text { (days) }\end{array}$ & $\begin{array}{c}\mathrm{m}_{\mathrm{p}} \\
(\mathrm{kg})\end{array}$ & $\begin{array}{c}\text { MET } \\
\text { (days) }\end{array}$ & $\begin{array}{c}\mathrm{m}_{\mathrm{p}} \\
(\mathrm{kg})\end{array}$ & $\begin{array}{c}\text { MET } \\
\text { (days) }\end{array}$ & $\begin{array}{c}\mathrm{m}_{\mathrm{p}} \\
(\mathrm{kg})\end{array}$ \\
\hline 0.0 & 78.2 & 511 & 71.8 & 553 & 61.3 & 642 \\
0.1 & 78.7 & 481 & 72.3 & 521 & 61.7 & 605 \\
0.2 & 79.8 & 456 & 73.4 & 494 & 62.7 & 574 \\
0.3 & 82.2 & 433 & 75.6 & 469 & 64.5 & 545 \\
0.4 & 85.6 & 414 & 78.7 & 448 & 67.2 & 521 \\
0.5 & 90.7 & 395 & 83.3 & 429 & 71.0 & 499 \\
0.6 & 98.6 & 379 & 90.6 & 411 & 77.3 & 477 \\
0.7 & 110.3 & 364 & 101.2 & 395 & 86.2 & 460 \\
0.8 & 131.1 & 351 & 120.6 & 381 & 102.8 & 443 \\
0.9 & 182.0 & 339 & 167.6 & 367 & 144.6 & 427 \\
\hline
\end{tabular}

As expected, trip time increases and propellant mass expenditure decreases in the discontinuous-thrust cases, shown in Table 2. 


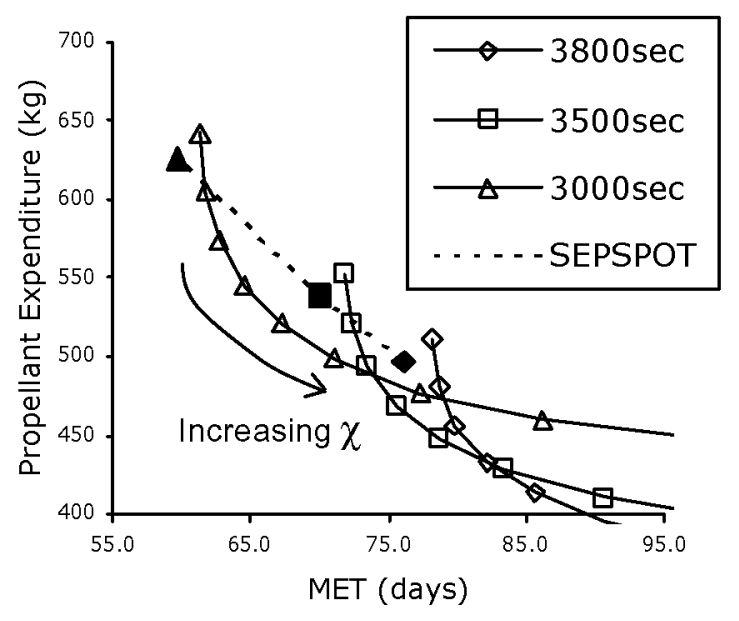

Figure 7: Trip Time vs. Propellant Mass Comparisons for Continuous-Thrust and Discontinuous-Thrust Inclination Changes in a Circular Orbit.

Figure 7, above, shows tradeoff in trip time and propellant expenditure in graphical form. The results of the SEPSPOT continuous-thrust cases (see Table 1) are shown for comparison.

For a given $\mathrm{I}_{\mathrm{sp}}$, increasing the value of $\chi$ can only reduce propellant mass compared to the continuousthrust case at the expense of trip time. However, reducing specific impulse and using an appropriate value for $\chi$ can achieve savings in both time and propellant consumption.

In this example, $\chi=0.0$ yields results that are inferior to the SEPSPOT results in both trip time and propellant mass. This discrepancy is a result of the fact that SEPSPOT optimizes only continuous-thrust cases. The solutions it finds utilize a portion of the spacecraft's thrust to increase the semi-major axis of the orbit, thereby increasing the magnitude of $\mathrm{di} / \mathrm{dt}$ throughout the orbit. The relationship between $\mathrm{di} / \mathrm{dt}$ and semi-major axis can be explained by starting with Equation 1 and the definitions of radius and mean motion $^{5}$. Equation 1 can be rewritten as

$$
\frac{d i}{d t}=\frac{W \sqrt{1-e^{2}} \cos (\omega+v)}{\sqrt{\frac{\mu}{a}}(1+e \cos (v))}
$$

Only the average change in $\mathrm{di} / \mathrm{dt}$ throughout an orbit is of interest, thus terms involving true-anomaly will be neglected. Also, since di/dt is proportional to the orbitnormal thrust magnitude, $\mathrm{W}$, the term is dropped. The relationship between the average value of $\mathrm{di} / \mathrm{dt}$ and semi-major axis can then be expressed as

$$
{\frac{d i}{d t_{\text {avg }}}} \propto \sqrt{\frac{\mu}{a}\left(1-e^{2}\right)}
$$

Figure 8 shows the relative value of $\mathrm{di} / \mathrm{dt}$, from Equation 14, throughout a SEPSPOT-generated transfer from Example 1.

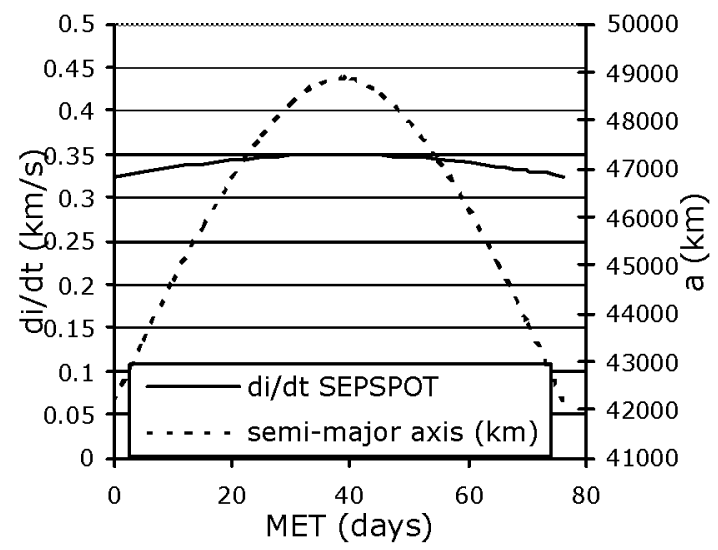

Figure 8: Relative Effect of Semi-Major Axis Change on $\mathrm{di} / \mathrm{dt}$

SEPSPOT achieves an increase in $\mathrm{di} / \mathrm{dt}$ of approximately $10 \%$ by increasing the semi-major axis for a portion of the transfer. The discontinuous-thrust cases run here use no in-plane thrust component to modify semi-major axis. Increased performance from the discontinuous-thrust case might be realized by directing thrust in-plane for di/dt inefficient portions of the orbit. However, the combination of the reduction of $I_{s p}$ and suspension of thrust throughout portions of the orbit can more than compensate for the difference in performance, even without changing the semi-major axis.

\section{Example 2: Eccentric Orbit Inclination Change, $\omega=0^{\circ}$}

The second example mission compares continuous and discontinuous-thrust inclination changes in a highly elliptic orbit. The maneuver transfers a spacecraft from an inclination of $28.45^{\circ}$ to a final inclination of $63.4^{\circ}$. Other orbital elements are not changed, and the semimajor axis and eccentricity of the orbit are the same as those for a Molniya orbit. Continuous-thrust and discontinuous-thrust results are shown in Tables 3 and 4 , respectively. 


$\begin{array}{ll}\text { Initial Orbit: } & \text { Final Orbit: } \\ \mathrm{a}=26600 \mathrm{~km} & \mathrm{a}=26600 \mathrm{~km} \\ \mathrm{e}=0.73 & \mathrm{e}=0.73 \\ i=28.45^{\circ} & i=63.4^{\circ} \\ \Omega=0^{\circ} & \Omega=0^{\circ} \\ \omega=0^{\circ} & \omega=0^{\circ}\end{array}$

Table 3: SEPSPOT Results for Example 2

\begin{tabular}{|c|c|c|}
\hline $\begin{array}{c}\mathrm{I}_{\mathrm{sp}} \\
(\mathrm{sec})\end{array}$ & $\begin{array}{c}\text { MET } \\
(\text { days })\end{array}$ & $\begin{array}{c}\mathrm{m}_{\mathrm{p}} \\
(\mathrm{kg})\end{array}$ \\
\hline 3800 & 53.9 & 352 \\
3500 & 49.5 & 382 \\
3000 & 42.3 & 444 \\
\hline
\end{tabular}

Table 4: Discontinuous-thrust Results for Example 2

\begin{tabular}{|c|c|c|c|c|c|c|}
\hline \multirow{2}{*}{$\chi$} & \multicolumn{2}{|c|}{$3800 \mathrm{sec}$} & \multicolumn{2}{c|}{$3500 \mathrm{sec}$} & \multicolumn{2}{c|}{$3000 \mathrm{sec}$} \\
\cline { 2 - 7 } & $\begin{array}{c}\text { MET } \\
(\text { days })\end{array}$ & $\begin{array}{c}\mathrm{m}_{\mathrm{p}} \\
(\mathrm{kg})\end{array}$ & $\begin{array}{c}\text { MET } \\
(\text { days })\end{array}$ & $\begin{array}{c}\mathrm{m}_{\mathrm{p}} \\
(\mathrm{kg})\end{array}$ & $\begin{array}{c}\text { MET } \\
(\text { days })\end{array}$ & $\begin{array}{c}\mathrm{m}_{\mathrm{p}} \\
(\mathrm{kg})\end{array}$ \\
\hline 0.0 & 58.0 & 379 & 53.3 & 411 & 45.6 & 478 \\
0.1 & 58.4 & 352 & 53.7 & 382 & 45.8 & 443 \\
0.2 & 59.6 & 328 & 54.8 & 354 & 46.8 & 412 \\
0.3 & 60.7 & 316 & 55.8 & 342 & 47.7 & 398 \\
0.4 & 62.5 & 304 & 57.6 & 330 & 49.2 & 384 \\
0.5 & 65.3 & 293 & 60.1 & 318 & 51.3 & 370 \\
0.6 & 69.7 & 283 & 64.2 & 307 & 54.8 & 357 \\
0.7 & 76.8 & 274 & 70.7 & 297 & 60.3 & 345 \\
0.8 & 90.1 & 264 & 82.7 & 287 & 70.7 & 334 \\
0.9 & 122.6 & 255 & 112.6 & 277 & 96.2 & 323 \\
\hline
\end{tabular}

For this case, a discontinuous-thrust inclination control law using only orbit-normal thrust can come close to the performance of SEPSPOT, as Figure 9 shows. Since $\mathrm{da} / \mathrm{dt}$ is at its maximum value at periapsis and $\mathrm{di} / \mathrm{dt}$ is at its maximum at apoapsis, SEPSPOT is able to increase the semi-major axis of the orbit and boost the magnitude of $\mathrm{di} / \mathrm{dt}$ while incurring almost a minimal gravity loss penalty. However, even with purely orbit normal thrust the discontinuous control law can come close to matching the performance of SEPSPOT.

If $\chi$ is significantly large such that the spacecraft is not thrusting out-of-plane at periapsis, a tangential thrust component or "perigee-hold" steering law can be introduced to modify the semi-major axis without taking any thrusting time away from the orbit-normal component. Greater efficiency can certainly be achieved through the use of a more complex control law that blends both in-plane and orbit-normal thrust in an effective manner.

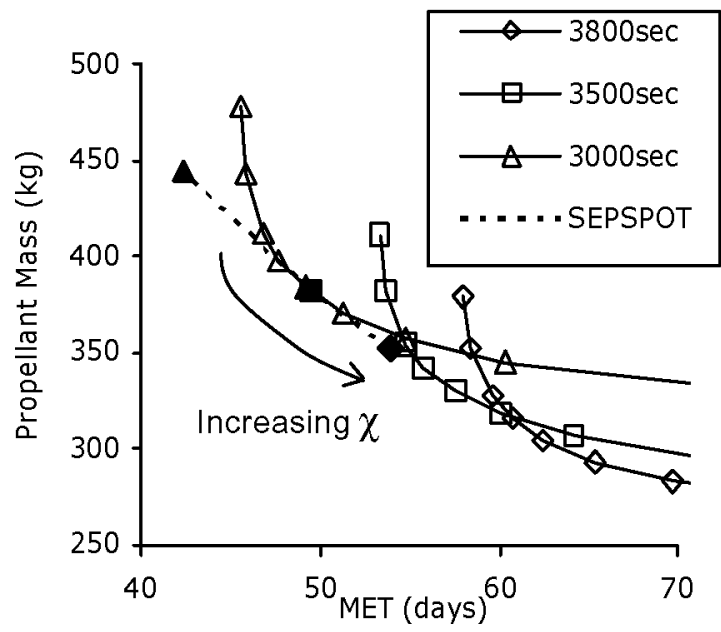

Figure 9: Trip Time vs. Propellant Mass Comparisons for Continuous-Thrust and Discontinuous-Thrust Inclination Changes in a Highly Elliptical Orbit, $\omega=0^{\circ}$

Example 3: Eccentric Orbit Inclination Change, $\omega=90^{\circ}$

For thoroughness, the inclination change performed in the previous example is reexamined for the case where $\omega=90^{\circ}$. All other orbital elements are the same as those in the previous example. The results for continuous-thrust and discontinuous-thrust cases are shown in Tables 5 and 6 , respectively.

Table 5: SEPSPOT Results for Example 3

\begin{tabular}{|c|c|c|}
\hline $\begin{array}{c}\mathrm{I}_{\mathrm{sp}} \\
(\mathrm{sec})\end{array}$ & $\begin{array}{c}\text { MET } \\
\text { (days) }\end{array}$ & $\begin{array}{c}\mathrm{m}_{\mathrm{p}} \\
(\mathrm{kg})\end{array}$ \\
\hline 3800 & 148.3 & 969 \\
3500 & 136.0 & 1057 \\
3000 & 115.5 & 1211 \\
\hline
\end{tabular}

Table 6: Discontinuous-thrust Results for Example 3

\begin{tabular}{|c|c|c|c|c|c|c|}
\hline$\chi$ & \multicolumn{2}{|c|}{$3800 \mathrm{sec}$} & \multicolumn{2}{c|}{$3500 \mathrm{sec}$} & \multicolumn{2}{c|}{$3000 \mathrm{sec}$} \\
\cline { 2 - 7 } & $\begin{array}{c}\text { MET } \\
(\text { days })\end{array}$ & $\begin{array}{c}\mathrm{m}_{\mathrm{p}} \\
(\mathrm{kg})\end{array}$ & $\begin{array}{c}\text { MET } \\
(\text { days })\end{array}$ & $\begin{array}{c}\mathrm{m}_{\mathrm{p}} \\
(\mathrm{kg})\end{array}$ & $\begin{array}{c}\text { MET } \\
(\text { days })\end{array}$ & $\begin{array}{c}\mathrm{m}_{\mathrm{p}} \\
(\mathrm{kg})\end{array}$ \\
\hline 0.0 & 144.4 & 943 & 132.3 & 1018 & 112.1 & 1175 \\
0.1 & 145.9 & 890 & 133.7 & 961 & 113.5 & 1110 \\
0.2 & 148.8 & 842 & 136.5 & 912 & 115.8 & 1051 \\
0.3 & 153.5 & 801 & 140.8 & 867 & 119.6 & 1002 \\
0.4 & 160.1 & 767 & 147.0 & 830 & 125.3 & 958 \\
0.5 & 170.0 & 735 & 156.5 & 791 & 133.5 & 912 \\
0.6 & 185.3 & 704 & 169.9 & 763 & 145.6 & 879 \\
0.7 & 210.5 & 676 & 192.8 & 733 & 164.0 & 850 \\
0.8 & 263.5 & 646 & 244.9 & 698 & 218.9 & 786 \\
0.9 & 397.9 & 571 & 363.9 & 615 & 316.4 & 737 \\
\hline
\end{tabular}




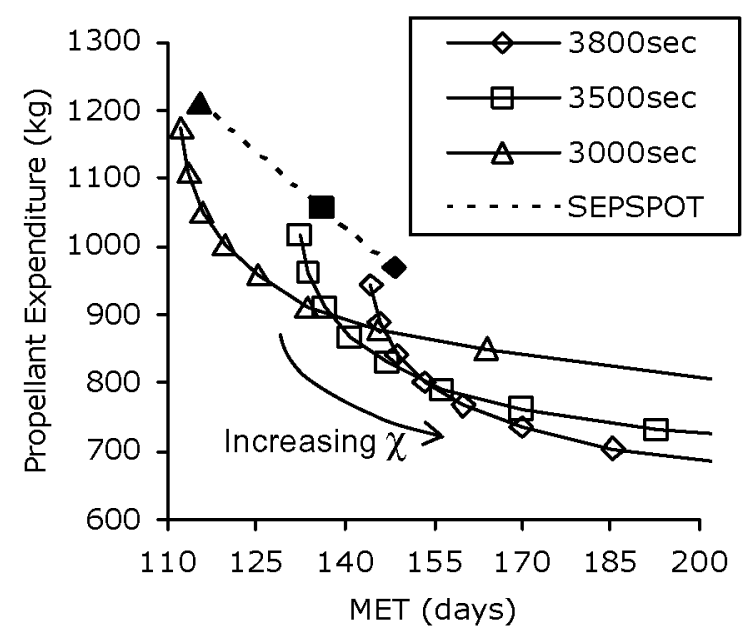

Figure 10: Trip Time vs. Propellant Mass Comparisons for Continuous-Thrust and Discontinuous-Thrust Inclination Changes in a Highly Elliptical Orbit, $\omega=90^{\circ}$

The results shown in Figure 10 indicate that the discontinuous-thrust control scheme is outperforming SEPSPOT at values of $\chi=0.0$ even at the same specific impulse. It is likely that since the magnitudes of both $\mathrm{da} / \mathrm{dt}$ and $\mathrm{di} / \mathrm{dt}$ are small near apoapsis, the fact that SEPSPOT is constrained to using continuous-thrust essentially wastes propellant during the apoapsis dwell. Even greater reductions in propellant and trip time can be achieved by reducing the specific impulse. The discontinuous-thrust control law is clearly preferable to continuous-thrust for inclination changes in orbits where periapsis occurs at or near the antinodes.

\section{CONCLUSIONS}

Using the discontinuous-thrust control law for inclination changes can reduce both the propellant load and the trip time required for an inclination-changing maneuver. While the performance benefits of such a method are dependent upon the argument of periapsis, it effectiveness has been demonstrated for both circular and highly elliptical orbits.

While the discontinuous-thrust control law presented here is capable of outperforming continuousthrust, calculus of variations solutions, like those generated by SEPSPOT, they are at the same time relatively simple. Through the use of this method, the mission designer has a significant amount of control in being able to modify the trip time for an inclination change maneuver to achieve an acceptable propellant expenditure, or vice versa.

\section{REFERENCES}

${ }^{1}$ Gefert, L.P., Hack, K.J.., Low-Thrust Control Law Development for Transfer from Low Earth Orbits to High Energy Elliptical Parking Orbits, Paper Number AAS 99-410, August 1999.

${ }^{2}$ Kluever, C., Simple Control Laws for Low-Thrust Orbit Transfers, Paper Number AAS 98-203.

Spaceflight Mechanics 1998, Volume 99, Part II, American Astronautical Society, 1998.

${ }^{3}$ Roy, A.E., Orbital Motion, Adam Hilger, Bristol, Philadelphia, and New York, 1991, p. 192

${ }^{4}$ Edelbaum, T.N., Malchow, H.L., Sacket, L.L., Solar Electric Geocentric Transfer with Attitude Constraints: Analysis, NASA CR 134927, August 1975.

${ }^{5}$ Bate, R.R., Mueller, D.D., White, J.E., Fundamentals of Astrodynamics, Dover Publications, New York, 1971, pp. 20, 185. 


\section{\begin{tabular}{l|l|l} 
1. AGENCY USE ONLY (Leave blank) & 2. REPORT DATE & 3. REPORT TYPE AND DATES COVERED
\end{tabular}}

4. TITLE AND SUBTITLE

October 2002

Technical Memorandum

5. FUNDING NUMBERS

A Method of Efficient Inclination Changes for Low-Thrust Spacecraft

6. AUTHOR(S)

WU-800-9B-20-00

Robert Falck and Leon Gefert

7. PERFORMING ORGANIZATION NAME(S) AND ADDRESS(ES)

National Aeronautics and Space Administration

John H. Glenn Research Center at Lewis Field

Cleveland, Ohio 44135-3191

8. PERFORMING ORGANIZATION

REPORT NUMBER

E-13553

9. SPONSORING/MONITORING AGENCY NAME(S) AND ADDRESS(ES)

10. SPONSORING/MONITORING

AGENCY REPORT NUMBER

National Aeronautics and Space Administration

Washington, DC 20546-0001

NASA TM-2002-211871

AIAA-2002-4895

\section{SUPPLEMENTARY NOTES}

Prepared for the Astrodynamics Specialist Conference and Exhibit cosponsored by the American Institute of Aeronautics and Astronautics and the American Astronautical Society, Monterey, California, August 5-8, 2002. Robert Falck, NASA Glenn Research Center, Student Engineer, and Leon Gefert, NASA Glenn Research Center. Responsible person, Robert Falck, organization code 7820, 216-433-2295.

12a. DISTRIBUTION/AVAILABILITY STATEMENT 12b. DISTRIBUTION CODE

Unclassified - Unlimited

Subject Category: 13

Distribution: Nonstandard

Available electronically at htp:/gitrs.grenasa.gov

This publication is available from the NASA Center for AeroSpace Information, 301-621-0390.

13. ABSTRACT (Maximum 200 words)

The evolution of low-thrust propulsion technologies has reached a point where such systems have become an economical option for many space missions. The development of efficient, low trip time control laws has received an increasing amount of attention in recent years, though few studies have examined the subject of inclination changing maneuvers in detail. A method for performing economical inclination changes through the use of an efficiency factor is derived front Lagrange's planetary equations. The efficiency factor can be used to regulate propellant expenditure at the expense of trip time. Such a method can be used for discontinuous-thrust transfers that offer reduced propellant masses and trip-times in comparison to continuous thrust transfers, while utilizing thrusters that operate at a lower specific impulse. Performance comparisons of transfers utilizing this approach with continuous-thrust transfers are generated through trajectory simulation and are presented in this paper.

\section{SUBJECT TERMS}

15. NUMBER OF PAGES

Low-thrust; Inclination; Spacecraft; SEPSPOT; SNAP

17. SECURITY CLASSIFICATION OF REPORT

Unclassified
18. SECURITY CLASSIFICATION OF THIS PAGE

Unclassified
19. SECURITY CLASSIFICATION OF ABSTRACT

Unclassified

NSN 7540-01-280-5500

16. PRICE CODE

\section{LIMITATION OF ABSTRACT}

